\title{
Study on Regional Cultural Soft Power and Its Translation
}

\author{
Runxia Cao
}

School of Foreign Studies, Xi' an University, 710065

\author{
Keywords: Regional Culture; Soft Power; Translation; Dialect
}

\begin{abstract}
National culture can enhance the country's cultural strength and penetrate into the country's economy, culture and politics. A good tradition of national culture can strengthen the country's international competitiveness. Chinese vast territory, diverse landforms and geographic spatial communication barriers gradually form the variety of regional culture with the passage of time. The spread of these regional cultures is conducive to the inheritance of the fine traditional national spirit. Besides, it is also conducive to the deep understanding of each region and achieves harmonious development. At the same time, it can also promote the local long-term development. This paper takes Shaanxi Province as an example, studying the main methods of translating its dialects and briefly discussing the significance of dialect translation. Finally, some innovative measures have been put forward through analyzing the present situation of translation activities.
\end{abstract}

\section{Introduction}

With the globalization process getting faster and faster, cultural exchanges between countries are becoming more frequent and deeper. Chinese culture changes quickly and is greatly affected by the western culture. Although the government pays attention to traditional culture, it is difficult to carry out into the public activities. To some extent, the western culture influences the values of contemporary young people, and the inheritance of traditional culture is imminent. In addition, Chinese regional dialect is full of cultural characteristics and shows part of the ancient culture with its deep historical background. And its inner connotation also has practical significance to contemporary life. Therefore, it is very important to study the spread of regional culture. This paper mainly takes Shaanxi dialect translation as an example to discuss the important role and main method of cultural heritage. The following is the main content.

\section{Present Situation of Shaanxi Dialect Translation}

Great Variety and Heavy Work Content. Shaanxi is geographically located in the northwest position and has longer geographical length of north-south direction[1]. Chinese cultural development has a more obvious ladder distribution in the north-south direction. The most obvious change can be found especially in the Qinling Mountains and Huaihe River line. Therefore, Shaanxi Province has many kinds of culture and there are some differences among its dialects. Moreover, the Qinling Mountains across Shaanxi Province and divide it into three parts. The south part of the Qinling Mountains is called Shannan, the north part is called Shanbei and the middle part is called Guanzhong. The cultural differences among the three regions are very large. The north part of Shaanxi is a typical loess plateau landscape, forming an impassioned regional culture, and its dialect nasal is heavier and has a certain ancient essays. For example, people named the natural phenomenon of lightning as "dragon grasping", which fully shows the rich imagination and artistic creativity of the ancients. The middle part of Shaanxi is a typical plain landscape which developed in ancient times with strong cultural characteristics, and the ancient farming developed here, forming a simple dialect culture. For example, the word "Rang" not only shows a strong flavor of culture, and expresses a kind of joking, but also conveys a more friendly and closely emotion. The south part of Shaanxi geographically belongs to the South, while its cultural environment is tend to be bold like the North. Therefore, its dialect has the local flavor of Shaanxi, but also the characteristics of the South[2]. For example, the word "Yan Jing Shui" in south part of Shaanxi means tears that contains a mild flavor of the South as well as contains a more popular atmosphere. 
The differences among these dialects have brought difficulties to the translation of Shaanxi dialects and increased the workload of translation.

Inadequate Translation in Original Information. Shaanxi dialect has a strong regional color. It brings difficulties in translation when they try to study the dialect without the local cultural environment. Some dialects have been somewhat difficult to express in Mandarin and it is even more difficult to translate them into other languages. For example, when translating "pot helmet like a lid", there will be a phenomenon that pot helmet is difficult to translate using other languages to accurately express. Besides, it will lose its original cultural connotation.

Single Translation Method and Poor Effect. At present, the translation of Shaanxi dialect mainly uses literal translation and liberal translation[3]. Literal translation is the direct conversion of words with less difficulty, but the expression of information is not accurate. Sometimes the meanings of expressions are exactly opposite because of the differences of cultural background. For example, during the international promotion about the ancient city of Xi'an, some relevant introduction about the ancient emperor will be made. When it comes to the word "dragon", most of the English translations are "Dragon". In fact, dragon was interpreted as a powerful evil force in most of the western cultures, which is contrary to the meaning of dragon in Chinese. Therefore, some English translation is "Chinese Dragon", but this translation is still ambiguous for some people who know nothing about Chinese culture. Liberal translation is to describe the meaning of the vocabulary. However, it takes lots of words to clarify the meaning. On the one hand, it will reduce its actual use. On the other hand, it will lose its original cultural connotation. For example, when translating "cover half of the house", some translators will describe the background, characteristics, main causes of formation and performance characteristics. Although the contents of translation are comprehensive and rich, it loses the original charm and communication value[4].

\section{The Significance of Translation Activities}

The excellent translation of the local culture can promote the people's recognition and heritage of culture, thus our fine traditions can have a good inheritance. In addition, the translation of regional culture can spread the national culture, which can not only resist the invasion of foreign bad culture, but also promote the essence of our culture and international status in the world, enhancing the vitality of the country and achieving the great rejuvenation of the nation. At last, the local government can enhance the local popularity through the translation of regional culture, contributing to the healthy development of local tourism[5-7].

Inherit National Culture and Build Harmonious Society. In dialect, there are many traditional cultural performances. A good translation of dialects enables people to have a good heritage of Chinese traditional culture and ultimately promote the harmonious development of the country. For example, the dialect "father and son love money make an unfilial son" shows correct values of the ancient Chinese people. It takes Confucian thought as the fundamental concept, integrating the values of filial piety and regarding the money lightly, and all of those show that the ancient people in Shaanxi value the spirit of harmony and regard the money lightly. Through the spread of these dialects, our people deepen the understanding of Shaanxi and have higher recognition to its spiritual connotation. Moreover, the spread of ideological realm of the ancient philosophers help promote the development of contemporary harmonious society. In dialect, it not only contains the harmonious and unified philosophy of the ancient people, but also includes a strong Confucian cultural connotation, which is in line with Chinese historical development rule[8-12].

Carry Forward Cultural Connotation and Realize National Rejuvenation. The translation of these dialects can enhance the vitality of traditional culture and minimize the impact of foreign culture. At the same time, it will promote the internationalization of our culture and improve our international status. Besides, Shaanxi has rich and profound cultural reserves, including the essence of traditional Chinese culture. Spreading our dialects to other countries can achieve a cultural blend and achieve the rejuvenation of the nation. For example, Confucius, a great philosopher of ancient China, has been praised by scholars around the world. These philosophical ideas are also used in dialects. For example, "Rich people read more books, poor people read less books", it shows the 
importance of education, which is a more unified understanding in the world. Through the dissemination of dialects, it can change some Westerners' misunderstanding of our country, which is conducive to cultural transmission.

Enhance Local Popularity and Promote Tourism Development. Shaanxi tourisms are well developed, especially in Xi'an which has become Chinese larger tourist city because of its deep cultural connotation. A good spread of these regional cultures not only helps visitors to experience the local folklore, but also helps outsiders to understand the local culture. For example, the publicity of "noodles like belt" is helpful for promoting the tourism, making this special food as a local cultural label.

\section{Innovative Measures of Translation Activities}

In order to improve the effect of translation and speed up the progress of related work, we need to strengthen the translation of dialects from the following aspects.

Follow Translation Principles and Achieve Cultural Exchanges. First of all, we should show the local cultural consciousness of Shaanxi, vigorously spread and protect the local culture and pay much attention to non-material cultural heritage. In addition, we also need to follow the principles of translation to enhance the rationality of translation.

Accuracy and Fluency. First, translation should meet the requirements of "accuracy", "idiomatic" and "elegance". It can not only retain the original charm of dialects, but also bring a good feeling to the translation viewers. Moreover, the expression of translation should be clear and the content is fluent, so that viewers can have an in-depth understanding when they read. It can be found that a good translation is full of fun seen by people who are proficient in both languages. The principle of translation put forward by Chinese translator, while the "functional equivalence" promoted by western countries also reflects this principle.

Cultural Transplant Transformation. Second, many dialects could not be translated directly, and liberal translation also has a high degree of difficulty. It can only achieve a poor effect and even take lots of words to clarify the meaning. At this time, translator can carry out cultural transplant transformation to look for the similarity between Shaanxi dialect and western language and then finish the transformation of translation. For example, the saying that "Full bottle water does not ring, half a bottle is sloshing." can be translated as "If water is noisy, there are no fish in it.". These two are the dialects of their respective regions. They not only show the irony to the rhetoric, but also show the admiration to the real scholars. This translation is the cultural transplant of the two cultures. It is very helpful for communication, but loses a lot of the original charm. As this translation is a reader-oriented translation, translator needs to consider carefully and chooses reasonably when translated in this way.

Alienation Strategy. In the translation of dialects, a lot of culture becomes difficult to be understood without the help of the local background information. Besides, the translation is not accurate if translators just consider the reader's feelings. Therefore, we need to take a certain alienation strategy to show the unique style of dialects when translating. For example, when translating the word "Kirin", it is difficult for foreigners to understand the unique Chinese beast. Using literal translation requires lots of words to clarify the meaning and is not conducive to cultural transmission. At the same time, it is difficult to achieve the docking of the two cultures when using cultural transplant transformation. In western culture, "Dragon" is closer to the image of "Kirin", but here is a world of difference between the cultural connotations of "Dragon" and "Kirin". Therefore, we can translate it into "Qi Lin" and add some notes. Through the alienation strategy, the local culture has been well preserved, which can leave a valuable cultural heritage for future generations.

Translate Flexibly and Retain Original Meaning. In translation, please do not rigidly adhere to the form. The goal of translation is to maximize the performance of the contents of the local dialect and preserve its original charm as much as possible. Using a variety of ways of translation can enhance its comprehensiveness.

Transliteration and Notes. For some local unique dialects, in order to express its original charm, 
it needs to be transliterated. For example, when translating "Mian Yu", it needs to be transliterated and add notes, which can show its playful characteristics and reflect the joy contained by food name.

Literal Translation and Liberal Translation. This kind of translation method can accurately express the meaning of the dialect and give full play to the advantages of liberal translation. At the same time, the literal translation needs to show its charm. For example, when translating "Zou Sa Le", it can be translated as "what's up?", and then add notes to explain the emotions of language, which has a slightly provocative emotional tendency.

Literal Translation and Notes. Sometimes, in order to get a more comprehensive expression of dialects, we can add some words on the basis of literal translation. For example, when translating "Yan Jing Shui", it will be translated as "Tear" to realize its meaning, which loses its original flavor. The original language is full of imagination and vividness, while "Tear" only means tears and it is a more common form of expression. Therefore, we can translate it into "Lucent Tear" which shows the south charm of Shaanxi dialect.

Translate from Multiple Perspectives and Enhance Expressions of Dialects. Translators need to consider the specific language environment and view it from multiple perspectives when translating dialects. In Chinese, the same word may have different meanings in different service environments, and sometimes even has the opposite meanings. For example, in southern Shaanxi dialect "Yang Tan" can be expressed as a hate for someone, meaning someone is a "fool". While, sometimes it is also a joke between friends which just shows a emotional tendency of joking, with a commendatory "fool" meaning. At this time, it can be translated as "fool" and "nerd", respectively has two meanings of "fool" and "simpleton". The relevant workers of the translation should fully consider the specific meaning and service environment to convey the original meaning of dialects accurately, combining with the emotional tendencies of the translation.

\section{Conclusion}

In this paper, it has a simple discussion about the inheritance and protection of regional culture, which takes Shaanxi dialect translation as an example. Good cultural heritage of the region can enhance the people's sense of identity of the national culture, thereby strengthening the internal cohesion. Moreover, cultural transmission can raise the international status of China, show the world with rich historical culture and support the nation's revitalization. This paper summarizes the present situation of Shaanxi dialect translation and puts forward some methods to improve the efficiency and effect of translation. In order to enhance the rationality of translation, some flexible methods were used to deeply study the local culture and other culture. It is hoped that the study of this paper may contribute to the regional cultural transmission in China and provide some useful advice for the relevant researchers.

\section{Acknowledgments}

Item Name: A Study on the Translation of Regional Dialects in Shaanxi from the Perspective of Culture in the Context of "the Belt and Road Initiative"

Item Number: 16WL17

\section{References}

[1] Y.T. Fan. On the Protection of Qiang Local Culture under the Transmission of Translation [J]. Sichuan Opera, 2014 (3): 93-96.

[2] F.P. Gao and X.M Liu. On the Translation Strategy of the "Get Out" in the Western Region Culture [J]. Journal of Weinan Teachers College, 2015, 30 (24): 49-53.

[3] W.G. Meng. A Masterpiece of the Study on the Translation of Chinese Regional Culture: A Review of Studies on the Translation of Regional Culture in Shaoxing of Lu Xun's Novels [J]. Journal of Shaoxing University of Arts and Sciences: Philosophy and Social Sciences, 2016,36 
(2): $38-40$.

[4] X.D. Gu and Z.F Liu. A Study on the Strategy of Translating Jiaxing Ancient Town Culture from the Perspective of Adaptation - A Case Study of Xitang Guiding Handbook [J]. Xinjiang Vocational Education Research, 2015,12 (4): 65-70.

[5] T.Teng, Z.L. Xiang and F.J. Wu, etc. Study the Problems and Countermeasures from the Functional Translation Theory of Xiangxi Culture Translation [J]. Technology Horizon, 2014 (20): 56-56.

[6] B.Y. Luo and X.Y. Zang. Study on Shaanxi Folk Customs Translation Strategy [J]. Test Weekly, 2015 (55): 18-18.

[7] N.Y. Wang. A Study on the Translation of Folk Songs in Guangxi under the Background of Cultural Output - A Case Study of French - speaking Countries [J]. Journal of Liuzhou Teachers College, 2014 (6): 32-35.

[8] N.Y. Wang. Translation Study of Ethnic Minority Folk Tourism Attractions under Cross-Cultural Communication Perspective - Guangxi Yiling Rock as an Example [J]. Tourism Overview Monthly, 2016 (12).

[9] F. Wu, Y.H. Yang and S.J. Luo. A Translation Study on the Model of Minority Culture Going out - A Case Study of Xiangxi National Culture [J]. Journal of Southwest University for Nationalities, Humanities and Social Sciences 2015,36 (10): 39-43.

[10]T.J. Xiao. Translation of Minority Cultures in China from the Perspective of Positive Discourse Analysis [J]. Journal of Guizhou University for Nationalities (Philosophy and Social Sciences), 2014 (6): 71-74.

[11] Y.C. Wang. Traditional Regional Cultural Landscape Protection Model based on the Landscape Fragmentation Analysis- Taking Zhibu Town, Zhuji City, Zhejiang Province as an Example [J]. Geography Research, 2011, 30 (1): 10-22.

[12]R. Xin, X.H.Kong and F.Z. Shao. Protection and Utilization of Regional Culture under the Background of the Protection of Intangible Cultural Heritage - Taking Dialect as an Example [J]. Hebei Journal, 2013, 28 (2): 201-203. 